\title{
Solubility of Rare Earth Chlorides (La, Nd, Er) in HCl Bearing Water Vapour from $350-425^{\circ} \mathrm{C}$
}

\author{
C. Alcorn, ${ }^{1}$ A. Strzelecki, ${ }^{1}$ H. Nisbet,${ }^{1}$ R. Currier, ${ }^{1}$ \\ R. ROBACK ${ }^{1}$ AND A. MIGDISOV ${ }^{1}$ \\ ${ }^{1}$ Earth and Environmental Science Division (EES-14), Los \\ Alamos National Laboratory, NM, USA, 87545 \\ (**Correspondence: calcorn@lanl.gov)
}

It has been demonstrated in the literature that high temperature water vapour can transport appreciable concentrations of metals (ie. $\mathrm{Cu}, \mathrm{Ag}, \mathrm{Au}, \mathrm{Mo}$, etc..) due to the formation of hydrated gas phase metal species. Interest in these processes has been rooted in genetic models of porphyry and epithermal ore deposits. Surprisingly, similar effects were found for rare earth elements (REEs), which are quite chemically different from those elements listed above. For this reason, we chose to quantitatively investigate the solubility of several REE chlorides ( $\mathrm{La}, \mathrm{Nd}$, and $\mathrm{Er}$ ) in $\mathrm{HCl}$ bearing water vapour from 350 to $425^{\circ} \mathrm{C}$. Density Functional Theory (DFT) methods have also been employed to interpret the thermodynamics (Gaussian 16).

The experimental method has been described in previous publications by the William-Jones group in Montréal, Canada. Results show that the fugacity of the hydrated metal complexes $\mathrm{MCl}_{3} \cdot n \mathrm{H}_{2} \mathrm{O}(\mathrm{M}=\mathrm{La}, \mathrm{Nd}, \mathrm{Er})$ increases linearly with the fugacity of water vapour until near-saturation conditions, corresponding to $n=1-2$ bound water molecules. DFT results give Gibbs Free Energies of formation $\left(\Delta G_{\mathrm{f}}\right)$ of -10.3 and $+8.3 \mathrm{~kJ} / \mathrm{mol}$ for the first two clusters $\mathrm{LaCl}_{3} \cdot \mathrm{H}_{2} \mathrm{O}$ and $\mathrm{LaCl}_{3} \cdot 2 \mathrm{H}_{2} \mathrm{O}$ at $350{ }^{\circ} \mathrm{C}$, giving us further confidence that $n=1-2$. Experiments also show that clusters with a very large number of water molecules form at near-saturation conditions, corresponding to a sharp increase in solubility. Although DFT predicts that these clusters correspond to an unfavourable $\Delta G_{\text {f }}$, these methods overlook the physics near a phase change, and are unreliable.

Experimental results conclude that fractionation of the individual REE in high temperature water vapour seems unlikely, however, there are large differences in the solubility of ( $\mathrm{La}, \mathrm{Nd}, \mathrm{Er}) \mathrm{Cl}_{3}$ compared to the economically undesirable $\mathrm{NaCl}$, as well as other valuable chloride salts such as $\mathrm{Cu}(\mathrm{I})$, $\operatorname{Ag}(\mathrm{I})$ and $\mathrm{Au}(\mathrm{I})$. DFT methods also prove valuable in evaluating and predicting solubilities in high temperature water vapour under ideal conditions. 